\title{
Basic science research article
}

COL6A1 related muscular dystrophy in Landseer dogs - a canine model for Ullrich congenital muscular dystrophy

Jan Brands, DVM ${ }^{1 *}$ Frank Steffen, DVM, ${ }^{2}$ Jochen Spennes, DVM ${ }^{3}$ Tosso Leeb, PhD, ${ }^{4}$ and Thomas Bilzer, DVM ${ }^{1}$

${ }^{1}$ Institute of Neuropathology, University Hospital Düsseldorf, Moorenstrasse 5, 40225

Düsseldorf, Germany

${ }^{2}$ Neurology Service, Department of Small Animals, Vetsuisse Faculty, University of Zurich, Winterthurerstrasse 260, 8050 Zurich, Switzerland

${ }^{3}$ Veterinary clinic Kaiserberg, Wintgensstrasse 81-83, 47058 Duisburg, Germany

${ }^{4}$ Institute of Genetics, Vetsuisse Faculty, University of Bern, Bremgartenstrasse 109a, 3001 Bern, Switzerland

\section{Acknowledgments}

The authors are grateful to the referring veterinarians, the Tierärztliche Praxis am Loh GmbH (Ennepetal, Germany) and also to all dog owners and breeders who donated samples and shared pedigree data of their dogs. Special thank goes to Dr. Armin Zaisser for helping in the preparation of this study.

This article has been accepted for publication and undergone full peer review but has not been through the copyediting, typesetting, pagination and proofreading process which may lead to differences between this version and the Version of Record. Please cite this article as doi: $10.1002 /$ mus.27162 
COL6A1 muscular dystrophy in Landseer dogs

*Corresponding author; e-mail: Janbrands@gmx.de (JB)

\section{Running title}

COL6A1 muscular dystrophy in Landseer dogs

\section{Ethical publication statement}

We confirm that we have read the Journal's position on issues involved in ethical publication and affirm that this report is consistent with those guidelines.

\section{Disclosure of conflicts of interest}

None of the authors has any conflict of interest to disclose. 
COL6A1 muscular dystrophy in Landseer dogs

COL6A1 related muscular dystrophy in Landseer dogs - a canine model for Ullrich congenital muscular dystrophy

\section{Abstract}

Introduction

Collagen VI related myopathies are congenital diseases of variable phenotype. The severe phenotype is referred to as Ullrich congenital muscular dystrophy. In this 
COL6A1 muscular dystrophy in Landseer dogs

study, we describe analoguos clinical signs and histopathological alterations in Landseer dogs.

\section{Materials}

We collected clinical data from 2 affected dogs and investigated the neuromuscular changes in 5 dogs from 2 different litters with immunohistochemistry and immunofluorescence. All affected dogs were homozygous for the p.Glu97* nonsense variant in the COL6A1 gene encoding the alpha-1 chain of collagen VI.

\section{Results}

Muscle biopsies revealed alterations similar to those in human patients with Ullrich congenital muscular dystrophy including the virtual absence of collagen $\mathrm{VI}$ in skeletal muscles.

\section{Discussion}

The clinical and pathological characterization of the affected Landseer dogs enhances the value of this animal model for human Ullrich congenital muscular dystrophy.

\section{Key words}


COL6A1 muscular dystrophy in Landseer dogs

collagen Vl; animal model; Ullrich congenital muscular dystrophy; canis lupus familaris

\section{Introduction}

Human collagen VI related congenital myopathies are commonly described as two different phenotypic forms, a mild form referred to as Bethlem myopathy (BM) and a severe form referred to as Ullrich congenital muscular dystrophy (UCMD).1,2,3,4 They are caused by genetic variants in COL6A1, COL6A2 or COL6A3, encoding the three subunits of collagen VI. ${ }^{5,6}$ Depending on the specific genetic variant, the severity of 
COL6A1 muscular dystrophy in Landseer dogs

the phenotypes and the mode of inheritance can vary. ${ }^{7,8} \mathrm{~A}$ complete list of all known functional human variants in the collagen VI genes can be found on the Leiden Muscular Dystrophy pages. ${ }^{9}$

Typical clinical signs of patients with UCMD are kyphosis, torticollis, hip dislocation, patella contracture, proximal contractures, distal joint hyperlaxity and protruding calcanei. ${ }^{10}$ From the muscular dystrophies described in dogs ${ }^{11,12}$ collagen VI related myopathies in Labrador Retriever dogs show an intermediate severity in comparison to human patients with BM or UCMD. The genetic origin has been identified as 2 different variants in COL6A3. In one, Labrador Retriever dog collagen VI was nearly absent in the sarcolemma but normal in the endomysium, while the other completely lacked collagen $\mathrm{VI}$ in muscle tissue. ${ }^{13,14}$

Dogs have been recognised as providing useful models for human hereditary disease ${ }^{15}$ and analogous diseases with similar phenotypes have also been described in DMD mutant dogs. ${ }^{16-19}$ Golden Retrievers carrying a DMD gene variant represent a valuable and widely used animal model for human Duchenne muscular dystrophy..$^{20}$ The canine model is of particular relevance because mice harbouring nonsense variants in the $D M D$ gene do not display the severe phenotypes seen in humans and dogs. ${ }^{21-23}$ 
COL6A1 muscular dystrophy in Landseer dogs

We previously identified the presumed causative genetic defect in the COL6A1 gene in Landseer dogs with a severe muscular dystrophy and provided an initial limited characterization of the clinical and histopathological phenotype. All affected dogs were homozygous for the mutant allele at a nonsense variant in COL6A1, p.Glu97*.24 In this report, we present the long-term follow up characterization of the clinical and pathological phenotype of the Landseer dogs and a comparative analysis between dogs and humans in order to provide the Landseer dog as a useful model for human UCMD.

\section{Materials and Methods}

\section{Ethics statement}

All dogs in this study were examined with the consent of their owners. The collection of blood samples was approved by the Cantonal Committee For Animal Experiments (Canton of Bern; permit 23/10). Clinical examinations of the affected Landseer dogs and their littermates including the collection of muscle biopsies were performed in the course of standard veterinary diagnostics, with the consent and on behalf of the dog owners. The clinical examinations therefore did not constitute an animal experiment in the legal sense and did not require ethical approval. 
COL6A1 muscular dystrophy in Landseer dogs

\section{Histopathological examinations}

A complete list of all muscles biopsied is summarized in Supplemental Table 1. All biopsies were measured, catalogued, subsequently frozen at $-135^{\circ} \mathrm{C}$ in isopentane and stored at $-80^{\circ} \mathrm{C}$ for further analysis. Additionally, the quadriceps femoris biopsy of one affected dog (S3) was fixed in $4 \%$ formaldehyde and embedded in paraffin. The frozen biopsies were cut into $7 \mu \mathrm{m}$ sections at $-20^{\circ} \mathrm{C}$ using a cryostat (CM 1900 , Leica Biosystems, Wetzlar, Germany). Samples were stained using haematoxylin and eosin (H\&E), modified Gomori trichrome according to Engel \& Cunningham (GT), oil red $\mathrm{O}$ and histochemically with acidic phosphatase, adenosine triphosphatase (ATPase) at pH 4.4 and pH 9.4 and nicotinamide adenine dinucleotide-tetrazolium reductase (NADH-TR).

Additional immunohistochemical stains for collagen IV (1:50, CIV22, Dako), collagen VI (1:1000, ab6588, Abcam; reacting with type specific epitopes), dystrophin 1 (1:100, NCL-DYS1, Novocastra), dystrophin 2 (1:100, NCL-DYS2, Novocastra), beta sarcoglycan (1:50, NCL-b-SARC, Novocastra), gamma sarcoglycan (1:100, NCL-gSARC, Novocastra), spectrin 1 (1:100, NCL-SPEC1, Novocastra) and emerin (1:50, NCL-EMERIN, Novocastra) were done. The anti-collagen VI antibody ab6588 is a rabbit polyclonal antibody that was raised against human native collagen alpha-1(VI). 
COL6A1 muscular dystrophy in Landseer dogs

All sections were examined under a light microscope (Leica DM 5000 B, Leica Microsystems, Wetzlar, Germany) at 100x, 400x and 1000x magnification. The illustrated pictures were taken with a light microscope camera (DFC 290, Leica Microsystems, Wetzlar, Germany).

Supplemental samples were incubated with antibodies for immunofluorescent labeling collagen IV (CIV22, Dako) and collagen VI (ab6588, Abcam; reacting with type specific epitopes). These were examined under a fluorescence microscope (Axio Imager 2, Carl Zeiss Microscopy, Wetzlar, Germany) in 100x, 400x and 1000x magnification.

The photomicrographs were taken with a light microscope camera (AxioCam MRm, Carl Zeiss Microscopy, Wetzlar, Germany).

\section{Results}

\section{Clinical presentation}

We obtained clinical data and blood test results from juvenile Landseer dogs of 2 different litters. Two affected dogs were born in Germany (G1, G2; both females and the only affected from a litter of 9; 2 littermates died within the first 24 hours) and 4 in Switzerland (S1-S4; 2 males and 2 females from a litter of 7). The 2 litters had 
COL6A1 muscular dystrophy in Landseer dogs

several common ancestors (Figure 1). Genetic testing of blood samples revealed a homozygous mutant at a nonsense variant, p.Glu97*, in the COL6A1 gene (Supplementary Figure 1). Affected dogs had severe signs of general muscle weakness and atrophy from the first weeks of life that had reached a severe level at the time of presentation. One affected male (S1) with profound clinical signs of muscle weakness was euthanised at an early age with no further investigation. Muscle atrophy was most striking in G2, a dog that achieved only $61 \%$ of the typical weight of a full grown female Landseer dog. ${ }^{24}$ Postural reactions, tendon reflexes (exception: reduced in G1), sensation and cranial nerve examination (exception: reduced gag reflex and megaoesophagus in S4) were normal. A generalised neuromuscular disease with predominant muscle dysfunction was evident so that lesion localization and muscle biopsies were obtained for further investigation. All affected dogs had to be euthanised at the age of 1 to 15 months due to the severity of their clinical signs and poor quality of life. Detailed clinical data and relevant blood test results of all 6 cases and the unaffected littermate are summarized in Table 1.

\section{Histopathological findings}

Individual pathologic lesions are summarized in Supplementary Table 1. H\&E and GT staining revealed a severely abnormal overall histologic morphology (Figure $2 \mathrm{C}-\mathrm{F}$ ). 
COL6A1 muscular dystrophy in Landseer dogs

In comparison to the unaffected sibling (Figure $2 \mathrm{~A}+\mathrm{B}$ ) the total amount of muscle fibres was markedly reduced. Reaction for acid phosphatase showed an increase of activitiy indicating degeneration and necrosis within muscle fibres. Oil red $\mathrm{O}$ staining indicated muscle inactivity and further highlighted the amount of adipose tissue. The alterations were more prominent in proximal than in distal muscles (S3, S4).

Staining for the oxidative enzymes ATPase and NADH-TR showed an indistinct distribution of type 1 and 2 fibres with no predominance of either type.

While immunohistochemical staining for dystrophin $1 \& 2$, beta sarcoglycan, gamma sarcoglycan, spectrin 1 and emerin were normal, staining for collagen VI revealed an absence in both sarcolemma and endomysium (Figure 3 B). Further immunofluorescence investigations for collgen VI showed similar results (Figure 4 $\mathrm{E}+\mathrm{H})$

\section{Discussion}

Muscle samples from affected dogs showed alterations commonly seen in muscular dystrophies. The lesions closely resembled those of human UCMD. ${ }^{26,27}$ Varying alterations demonstrate different stages of muscular destruction with compensatory hypertrophy and progressive replacement of lost fibres by connective and adipose tissue. These histopathological findings are also a common feature of the severe 
COL6A1 muscular dystrophy in Landseer dogs

Duchenne muscular dystrophy of Golden Retrievers with a genetic defect in the Xlinked $D M D$ gene coding for dystrophin. ${ }^{21-23}$ However, myofiber necrosis in the COL6A1/- Landseer dogs was generally less prominent and the mitochondria had no substantial alterations such as ragged red fibres. ${ }^{20} \mathrm{CK}$ elevation was only mild to moderate, similar to human UCMD patients, ${ }^{4}$ while CK in the affected Golden Retrievers is highly increased and a helpful tool in diagnosis. ${ }^{22} \mathrm{~A}$ comparison of the clincal and histopathological hallmarks between UCMD, BM, Col6a1\% knock out mice and the affected Landseer dogs is summarised in Table 2.

All muscle biopsies lacked antibody reaction to collagen VI in the sarcolemma and showed only weak immunofluorescence in the endomysium. A plausible explanation could be nonspecific reactions of the anti-collagen alpha-1(VI) antibodies to epitopes located on other extracellular collagen VI subunits that are not affected by the p.Glu97* nonsense variant in the COL6A1 gene. Alternatively, it might result from cross reactions with other proteins or variability of the antibodies used. ${ }^{28}$ Muscle atrophy and adipose tissue distribution in G2 was excessive and present in both superficial gluteus and semimembranosus muscle (Figure $3 \mathrm{C}$ ). As the genetic diagnosis was not known during the course of the disease, most of the investigated dogs received only symptomatic support. Analogous therapy as in human patients could possibly slow down disease progression as seen in $\mathrm{G} 2$, which may have achieved the longest survival because the dog received the most aggressive 
COL6A1 muscular dystrophy in Landseer dogs

symptomatic support (i.e. physiotherapy with use of an underwater treadmill) until the last possible point in time. We believe that the observed dramatic muscle atrophy and histopathologic picture of $\mathrm{G} 2$ represents the end stage of the disease. A canine muscular dystrophy with a comparable clinical picture and prominent histopathologic fatty change in distal muscle biospies has been described in Rottweiler dogs. In contrast to the Landseer dogs that showed a proximal distribution, similar to humans with $\mathrm{UCMD}^{4}$, these dogs developed a distal myopathy caused by a presumed defect in the sarcolemmal transport of carnitine. ${ }^{29}$

The complete lack of collagen VI and the severe clinical phenotype, resembling human patients with UCMD, also differentiates the affected COL6A1 ${ }^{-1-}$ Landseer dogs from the 2 described Labrador Retriever dogs with variants in COL6A3 that showed milder ("BM like") phenotypes. One Labrador dog carried a recessive allele with a premature stop codon in a homozygous state (COL6A3:p.R1576*). Immunolabeling in this dog revealed a complete lack of collagen VI in skeletal muscles, while the other dog showed a sarcolemma specific collagen VI deficiency. The second dog carried a dominant allele in a heterozygous state leading to altered splicing (COL6A3:c.6210+1G>A) ${ }^{13,14}$ As in humans with collagen $\mathrm{VI}$ alterations, the clinical severity in dogs is most likely variable and dependent on the specific genetic variant. UCMD is the most severe phenotype with progressive weakness and muscle contractures. Affected patients lose the ability to walk within the first or second 
COL6A1 muscular dystrophy in Landseer dogs

decade of life. BM has milder clinical signs and longer periods of unassisted ambulation. ${ }^{8}$

Col6a1 ${ }^{-/}$knockout mice are an animal model for collagen VI related congenital muscular dystrophies/BM. ${ }^{30}$ Although they do not express any residual collagen alpha-1(VI) chains, the mice lack the severe phenotype of UCMD. In contrast, the affected Landseer dogs showed a severe and clinically relevant phenotype, much closer to the human condition.

Electron micrsocopy of Col6a1 ${ }^{-/-}$knock out mice muscle cells showed mitochondrial tubular cristae, electron-dense inclusions, overt swelling and additional marked dilations of the sarcoplasmic reticulum. These alterations are due to mitochondrial dysfunction. ${ }^{31}$ Treatment with cyclosporine A leads to the inhibition of the mitochondrial permeability transition pore. In Col6a1 ${ }^{-/-}$mice this rescued the ultrastructural defects in muscle and markedly decreased the number of apoptotic nuclei in vivo. ${ }^{32}$ Mitochondrial defects can also be seen in human patients with genetic defects in COL6A1 or COL6A3 gene. ${ }^{33}$ Consequently, further investigations of the Landseer UCMD should comprise electron microscopy, which was not possible in the present study because glutaraldehyde-fixed material was not available).

There is currently no cure for human patients with a collagen VI related congenital muscular dystrophy. Management consists of physiotherapy, orthopaedic treatment, 
COL6A1 muscular dystrophy in Landseer dogs

surgery and respiratory support. ${ }^{34,35}$ Six human patients were treated with cyclosporine A (3-5 mg/kg) over 1 to 3.2 years in an open trial study. Treatment corrected mitochondrial dysfunction, increased muscle regeneration and decreased the number of apoptotic nuclei. This resulted in improvement of muscle strength, but did not affect motor function or further detoriation of respiratory function. ${ }^{35}$ In conclusion, we provide a refined clinical and histopathological description of a collagen VI related severe canine muscular dystrophy. The Landseer dogs carrying the COL6A1 nonsense variant in a homozygous state could potentially be used in place of Col6a1 ${ }^{-/}$knock out mice for final tests before human clinical trials of a novel therapy for human UCMD, as their clinical phenotype more closely resembles the human situation. A genetic test for the COL6A1:p.Glu97* nonsense variant in dogs is commercially available and can be used to establish a colony starting from heterozygote carriers (Figure 1). ${ }^{36}$

\section{Abbreviations:}

ATPase adenosine triphosphatase

BM

Bethlem myopathy

BMD Becker muscular dystrophy 
COL6A1 muscular dystrophy in Landseer dogs

CK creatine kinase

Col6a1 ${ }^{--} \quad$ mice with two null allels in the Col6a1 gene encoding collagen type VI alpha 1 chain

COL6A1 $1^{--} \quad$ Landseer dogs with two null allels in the COL6A1 gene encoding collagen type VI alpha 1 chain

COL6A1 gene encoding collagen type VI alpha 1 chain

COL6A2 gene encoding collagen type VI alpha 2 chain

COL6A3 gene encoding collagen type VI alpha 3 chain

GT modified Gomori trichrome according to Engel \& Cunningham

G1 affected dog 1 from Germany

G2 affected dog 2 from Germany

H\&E haematoxylin and eosin

NADH-TR nicotinamide adenine dinucleotide-tetrazolium reductase

S1

affected dog 1 from Switzerland

S2

affected dog 2 from Switzerland

S3

affected dog 3 from Switzerland 
COL6A1 muscular dystrophy in Landseer dogs

S4

affected dog 4 from Switzerland

S5

control dog from Switzerland

UCMD Ullrich congenital muscular dystrophy

\section{References}

1. Ullrich O. Kongenitale, atonisch-sklerotische Muskeldystrophie, ein weiterer Typus der heredodegenerativen Erkrankungen des neuromuskulären Systems. Zeitschrift für die gesamte Neurologie und Psychiatrie 1930; 126:171-201.

2. Ullrich O. Kongenitale, atonisch-skelerotische Muskeldystrophie. Monatsschr. Kinderheilkd. 1930; 47:502-510.

3. Bethlem J, van Wijngaarden GK. Benign myopathy, with autosomal dominant inheritance. A report on three pedigrees. Brain 1976; 99:91-100.

4. Flanigan KM. The muscular dystrophies. Semin. Neurol. 2012; 32:255-263. 
COL6A1 muscular dystrophy in Landseer dogs

5. Jöbsis GJ, Keizers H, Vreijling JP, de Visser M, Speer MC, Woltermann RA, et al. Type VI collagen mutations in Bethlem myopathy, an autosomal dominant myopathy with contractures. Nat. Genet. 1996; 14:13-115.

6. Camacho Vanegas O, Bertini E, Zhang RZ, Petrini S, Minosse C, Sabatelli P, et al. Ullrich scleroatonic muscular dystrophy is caused by recessive mutations in collagen type VI. Proc. Natl. Acad. Sci. U. S. A. 2001; 98:7516-7521.

7. Allamand V, Briñas L, Richard P, Stojkovic T, Quijano-Roy S, Bonne G. ColVI myopathies: where do we stand, where do we go? Skelet. Muscle 2011; 1:30.

8. Bönnemann CG. The collagen VI-related myopathies: muscle meets its matrix. Nat. Rev. Neurol. 2011; 7:379-90.

9. http://www.dmd.nl/ 
COL6A1 muscular dystrophy in Landseer dogs

10. Yonekawa T, Nishino I. Ullrich congenital muscular dystrophy: clinicopathological features, natural history and pathomechanism(s). J. Neurol. Neurosurg. Psychiatry 2015, 86:280-287.

11. Shelton GD, Engvall E, Muscular dystrophies and other inherited myopathies. Vet. Clin. North Am. Small Anim. Pract. 2002; 32:103-124.

12. Barth'el'emy I, Hitte C, Tiret L. The Dog Model in the Spotlight: Legacy of a Trustful Cooperation. Neuromuscul Dis. 2019; 6:421-451.

13. Marioni-Henry K, Haworth P, Scott H, Witte P, Guo LT, Shelton GD. Sarcolemmal specific collagen VI deficient myopathy in a Labrador Retriever. J. Vet. Intern. Med. 2014; 28:243-249.

14. Bolduc V, Minor KM, Hu Y, Kaur R, Friedenberg SG, van Buren S, et al. Pathogenic variants in COL6A3 cause Ullrich-like congenital muscular dystrophy in young Labrador Retriever dogs. Neuromul Disord. 2020; 30:360-367. 
COL6A1 muscular dystrophy in Landseer dogs

15. Shelton GD, Engvall E. Canine and feline models of human inherited muscle diseases. Neuromuscul. Disord. 2005; 15:127-138.

16. Sharp NJ, Kornegay JN, Van Camp SD, Herbstreith MH, Secore SL, Kettle S, et al. An error in dystrophin mRNA processing in golden retriever muscular dystrophy, an animal homologue of Duchenne muscular dystrophy. Genomics 1992; 13:115121.

17. Smith BF, Yue Y, Woods PR, Kornegay JN, Shin JH, Williams RR, et al. An intronic LINE-1 element insertion in the dystrophin gene aborts dystrophin expression and results in Duchenne-like muscular dystrophy in the corgi breed. Lab Invest. 2011; 91:216-231.

18. Atencia-Fernandez S, Shiel RE, Mooney CT, Nolan CM. Muscular dystrophy in the Japanese Spitz: an inversion disrupts the DMD and RPGR genes. Anim Genet. 2015; 46:175-184.

19. Jenkins CA, Forman OP. Identification of a novel frameshift mutation in the 
COL6A1 muscular dystrophy in Landseer dogs

DMD gene as the cause of muscular dystrophy in a Norfolk terrier dog.

Canine Genet Epidemiol. 2015; 2:7.

20. Kornegay JN. The golden retriever model of Duchenne muscular dystrophy. Skelet Muscle 2017; 7:9.

21. Cooper BJ, Winand NJ, Stedman H, Valentine BA, Hoffman EP, Kunkel LM, et al. The homologue of the Duchenne locus is defective in X-linked muscular dystrophy in dogs. Nature 1988; 334:154-156.

22. Valentine BA, Cooper BJ, de Lahunta A, O'Quinn R, Blue TJ. Canine X-linked muscular dystrophy. An animal model of Duchenne muscular dystrophy: clinical studies. J. Neurol. Sci. 1988; 88:69-81.

23. Valentine BA, Winand NJ, Pradhan D, Moise NS, de Lahunta A, Kornegay JN, et al. Canine X-linked muscular dystrophy as an animal model of Duchenne muscular dystrophy: a review. Am. J. Med. Genet. 1992; 42:352-356. 
COL6A1 muscular dystrophy in Landseer dogs

24. Steffen F, Bilzer T, Brands J, Golini L, Jagannathan V, Wiedmer M, et al. A Nonsense Variant in COL6A1 in Landseer Dogs with Muscular Dystrophy. G3 (Bethesda) 2015; 5:2611-2617.

25. http://www.fci.be/Nomenclature/Standards/050g02-en.pdf

26. Histological and Histochemical changes. In: Dubowitz V, Sewry CA, Oldfors A. Muscle Biopsy: A Practical Approach, 4th ed. London: Saunders Elsevier; 2013. p. 55-94.

27. Muscular dystrophies and allied disorders III: Congenital muscular dystrophies and associated disorders. In: Dubowitz V, Sewry CA, Oldfors A. Muscle Biopsy: A Practical Approach, 4th ed. London: Saunders Elsevier; 2013. p. 302-319.

28. Baker M. Reproducibility crisis: Blame it on the antibodies. Nature 2015; 521:74276. 
COL6A1 muscular dystrophy in Landseer dogs

29. Hanson SM, Smith MO, Walker TL, Shelton GD. Juvenile-onset distal myopathy in Rottweiler dogs. J. Vet. Intern. Med. 1998; 12:103-108.

30. Bonaldo P, Braghetta P, Zanetti M, Piccolo S, Volpin D, Bressan GM. Collagen VI deficiency induces early onset myopathy in the mouse: an animal model for Bethlem myopathy. Hum. Mol. Genet. 1998; 7:2135-2140.

31. Irwin WA, Bergamin N, Sabatelli P, Reggiani C, Megighian A, Merlini L, et al. Mitochondrial dysfunction and apoptosis in myopathic mice with collagen $\mathrm{VI}$ deficiency. Nat. Genet. 2003; 35:367-371.

32. Angelin A, Tiepolo T, Sabatelli P, Grumati P, Bergamin N, Golfieri C, et al. Mitochondrial dysfunction the pathogenesis of Ullrich congenital muscular dystrophy and prospective therapy with cyclosporins. Proc. Natl. Acad. Sci. U. S. A. 2007; 104:991-996. 
COL6A1 muscular dystrophy in Landseer dogs

33. Merlini L, Bernardi P. Therapy of Collagen VI-Related Myopathies (Bethlem and Ullrich). Neurotherapeutics 2008; 5:613-618.

34. Wang CH, Dowling JJ, North K, Schroth MK, Sejersen T, Shapiro F, et al. Consensus statement on standard care of care for congenital myopathies. J. Child. Neurol. 2012; 27:362-382.

35. Merlini L, Sabatelli P, Armaroli A, Gnudi S, Angelin A, Grumati P, et al. Cyclosporine A in Ullrich congenital muscular dystrophy: long-term results. Oxid. Med. Cell Longev. 2011; 2011:139194.

36. http://www.animalabs.com/shop/dogs/landseer-muscular-dystrophy-mdl/

\section{Figure 1}

Pedigree of the investigated dogs. 
COL6A1 muscular dystrophy in Landseer dogs

The six affected dogs (S1-S4, G1, G2) originated in two litters from Switzerland and Germany. The German litter on the right side is inbred to a great-great-grandfather shown at the top right of the pedigree. Three key ancestors marked with asterisks are shared by both litters. Genotypes at COL6A1:c.289G>T are indicated for those dogs from which a DNA sample was available.

\section{Figure 2}

Histopathology of quadriceps femoris biopsies.

$(A+B)$ unaffected littermate at 4.5 months (S5); (C+D) affected female dog at 8 months (G1); (E+F) affected male dog at 4 months (S2). (A, C, E) H\&E staining. (B, D, F) GT staining.

$(A+B)$ Normal muscle histologic morphology without significant pathological changes. Muscle and fibre size configuration and variation, sarcolemma, nuclear structure and distribution as well as perimysial and endomysial connective tissue are of physiological appearance.

(C, D, E, F) Muscle fibres show an abnormal and inhomogeneous variation in size and configuration, indicating fibre hyperthrophy and atrophy. The shape of most fibres is round instead of polygonal and distribution of enlarged and small fibres was random and diffuse, implying the cause of the alterations to be of myopathic origin. 
COL6A1 muscular dystrophy in Landseer dogs

Additionally, occasional central nuclei (arrows) and basophilic regeneration are visible. Fibre loss is accompanied by remarkable excess and distortion of both perimysial (stars) and endomysial connective tissue combined with the abundance of adipose tissue.

(A, B, C, D) 1000x magnification, bar $20 \mu \mathrm{m} .(E+F)$ 400x magnification, bar $50 \mu \mathrm{m}$.

\section{Figure 3}

Immunohistochemistry of quadriceps femoris biopsies for collagen VI and end stage disease picture of a superficial gluteus biopsy.

(A) Unaffected littermate at 4.5 months (S5); (B) affected female dog at 8 months (G1); (C+D) affected female dog at 15 months (G2).

$(\mathrm{A}+\mathrm{B})$ Immunostaining for collagen VI. Collagen VI (indicated by dark colour) is present in both sarcolemma and endomysium of the unaffected littermate (A) and absent in the affected dog (B).

(C+D) H\&E stained end stage picture of the disease. Large amounts of pale necrotic fibres (arrows) and a "moth eaten" histologic appearance with excessive replacement by adipose tissue. The muscle biopsy is embedded in mounting medium (stars). 
COL6A1 muscular dystrophy in Landseer dogs

(A) 1000x magnification, bar $20 \mu \mathrm{m}$; (B) 400x magnification, bar $50 \mu \mathrm{m}$; (C) 100x magnification, bar $200 \mu \mathrm{m}$. (D) 1000x magnification, bar $20 \mu \mathrm{m}$.

\section{Figure 4}

Double immunofluorescence of quadriceps femoris biopsies for collagen IV and VI. (A-C) Unaffected littermate at 4.5 months (S5); (D-F) affected female dog at 8 months (G1); (G-I) affected male dog at 4 months (S2).

$(A, D, G)$ Immunofluorescence for collagen IV (green colour). Collagen IV is present in all dogs.

$(\mathrm{B}, \mathrm{E}, \mathrm{H})$ Immunfluorescence for collagen $\mathrm{VI}$ (red colour). Collagen $\mathrm{VI}$ is absent from the sarcolemma of the affected dogs. Small spots in the endomysium of the affected dogs probably represent unspecific epitopes not related to collagen alpha-1(VI) subunits.

$(\mathrm{C}, \mathrm{F}, \mathrm{I})$ Merged images. Both collagen IV and $\mathrm{VI}$ are present in the unaffected littermate (yellow colour); the affected dogs show only small spots of yellow colour in the endomysium.

1000x magnification, bar $20 \mu \mathrm{m}$. 


\section{Table 1 Clinical data}

\begin{tabular}{|c|c|c|c|c|c|c|c|}
\hline Subject & G1 ${ }^{\top}$ & G2" & S1" & S2" & S3" & S4T & S5" \\
\hline Gender & Female & Female & Male & Female & Male & Female & Female \\
\hline $\begin{array}{l}\text { Genotype at } \\
\text { COL6A1:p.Glu }\end{array}$ & $\mathrm{T} / \mathrm{T}$ & $\mathrm{T} / \mathrm{T}$ & $T / T$ & $\mathrm{~T} / \mathrm{T}$ & $T / T$ & $\mathrm{~T} / \mathrm{T}$ & $\mathrm{G} / \mathrm{T}$ \\
\hline Age at onset & 8 weeks & 2-3 weeks & 2-3 weeks & 2-3 weeks & 2-3 weeks & 2-3 weeks & No onset \\
\hline Clinical signs & $\begin{array}{l}8 \text { weeks: } \\
\text { plantigrade stance, } \\
\text { simutaneous lifting } \\
\text { of both hindlimbs } \\
\text { while walking } \\
7 \text { months: non- } \\
\text { ambulatory, } \\
\text { elevated body } \\
\text { temperature } \\
\text { (39.6 } 6^{\circ} \text { ), highly } \\
\text { prominent muscle } \\
\text { atrophy with } \\
\text { proximal } \\
\text { dominance, } \\
\text { thickend and }\end{array}$ & $\begin{array}{l}\text { 2-3 weeks: palmi- } \\
\text { and plantigrade } \\
\text { stance } \\
4 \text { weeks: reluctance } \\
\text { to move } \\
4 \text { months: proximal } \\
\text { joint contractures } \\
5 \text { months: } \\
\text { generalised muscle } \\
\text { atrophy with } \\
\text { proximal } \\
\text { dominance, } \\
\text { unsecure } \\
\text { hypometric gait with } \\
\text { falling down }\end{array}$ & $\begin{array}{l}\text { No further details } \\
\text { were provided }\end{array}$ & $\begin{array}{l}4 \text { months: } \\
\text { prolonged sleeping } \\
\text { episodes, } \\
\text { reluctance to } \\
\text { move, short strided } \\
\text { gait, muscle } \\
\text { atrophy, proximal } \\
\text { joint contractures } \\
\text { and pain on } \\
\text { palpation }\end{array}$ & $\begin{array}{l}4 \text { months: } \\
\text { prolonged sleeping } \\
\text { episodes, } \\
\text { reluctance to } \\
\text { move, short strided } \\
\text { gait, muscle } \\
\text { atrophy, proximal } \\
\text { joint contractures } \\
\text { and pain on } \\
\text { palpation }\end{array}$ & $\begin{array}{l}4 \text { months: non- } \\
\text { ambulatory, } \\
\text { elevated body } \\
\text { temperature } \\
\left(39.6^{\circ} \mathrm{C}\right), \text { highly } \\
\text { prominent muscle } \\
\text { atrophy, reduced } \\
\text { gag reflex, } \\
\text { megaoesophagus, } \\
\text { aspiration } \\
\text { pneumonia }\end{array}$ & $\begin{array}{l}\text { No abnormal } \\
\text { findings }\end{array}$ \\
\hline
\end{tabular}


Table 2 Comparison of human, murine and Landseer dogs collagen VI related muscular dystrophies

\begin{tabular}{|c|c|c|c|c|}
\hline $\begin{array}{l}\text { Type of collagen VI related } \\
\text { muscular dystrophy }\end{array}$ & $\begin{array}{l}\text { Ullrich congenital muscular } \\
\text { dystrophy }\end{array}$ & Bethlem Myopathy & Col6a1 ${ }^{-/}$knock out mice & $\begin{array}{l}\text { Landseer dogs homozygous } \\
\text { for p.Glu97* nonsense variant } \\
\text { in COL6A1 }\end{array}$ \\
\hline Clinical features & $\begin{array}{l}\text { Severe progressive muscle } \\
\text { weakness and hypotonia, } \\
\text { hyperlaxity of distal and } \\
\text { contractures of proximal joints, } \\
\text { dislocation of hips, delayed } \\
\text { ambulation (achieved in some } \\
\text { but not all), round face with } \\
\text { prominent ears, hyperkeratosis } \\
\text { and abnormal scar formation, } \\
\text { progressive respiratory } \\
\text { insufficiency leading to } \\
\text { respiratory failure, prominent } \\
\text { calcanei, scoliosis, CK normal } \\
\text { or mildly elevated }\end{array}$ & $\begin{array}{l}\text { Commonly long finger flexor and } \\
\text { sometimes ellbow and ancle } \\
\text { contractions, mild progressive } \\
\text { muscle weakness (proximal > } \\
\text { distal), respiratory insufficiency } \\
\text { may appear after 4th decade, } \\
\text { CK }^{\#} \text { normal or mildly elevated }\end{array}$ & $\begin{array}{l}\text { No obvious muscular phenotype, } \\
\text { reduced skin tensile strength }\end{array}$ & $\begin{array}{l}\text { Severe progressive muscle } \\
\text { weakness and hypotonia, } \\
\text { hyperlaxity of distal and } \\
\text { contractures of proximal joints in } \\
\text { some cases, later all cases with } \\
\text { proximal and distal joint } \\
\text { contractures, CK } \text { K }^{\#} \text { mild to } \\
\text { moderate elevated, non } \\
\text { ambulatory at } 4-15 \text { months, } \\
\text { megaoesophagus and aspiration } \\
\text { pneumonia in } 1 \text { case }\end{array}$ \\
\hline Histopathologic lesions & $\begin{array}{l}\text { Abnormal variation in fibre size, } \\
\text { round fibre shape, fibre atrophy, } \\
\text { internal nuclei, extensive amount } \\
\text { of endomysial connective tissue, } \\
\text { necrotic fibres, basophilic } \\
\text { regenerating fibres, indistinct } \\
\text { fibre type or predominance of } \\
\text { type } 1 \text {, immunolabeling: } \\
\text { complete lack of collagen VI in } \\
\text { skeletal muscles or just in the } \\
\text { sarcolemma }\end{array}$ & $\begin{array}{l}\text { Same changes as Ullrich } \\
\text { congenital muscular dystrophy } \\
\text { but less distinctive alterations, } \\
\text { immunolabeling: often no } \\
\text { reduction in collagen } \mathrm{VI}\end{array}$ & $\begin{array}{l}\text { General signs of myopathy: } \\
\text { muscle necrosis and } \\
\text { phagocytosis, pronounced } \\
\text { variation in fibre diameter, } \\
\text { hypercontracted and necrotic } \\
\text { fibres, most frequent in } \\
\text { Diaphragm (up to } 20 \% \text { fibres) } \\
\text { but also in intercostal, external } \\
\text { oblique, straight abdominal and } \\
\text { medial femoral muscles, } \\
\text { immunolabeling: complete lack } \\
\text { of collagen VI in skeletal } \\
\text { muscles }\end{array}$ & $\begin{array}{l}\text { Abnormal variation in fibre size, } \\
\text { round fibre shape, fibre atrophy, } \\
\text { internal nuclei, extensive amount } \\
\text { of endomysial connective tissue, } \\
\text { necrotic fibres, basophilic } \\
\text { regenerating fibres, indistinct } \\
\text { fibre type or predominance of } \\
\text { type 1, immunolabeling: } \\
\text { complete lack of collagen VI in } \\
\text { skeletal muscles }\end{array}$ \\
\hline
\end{tabular}




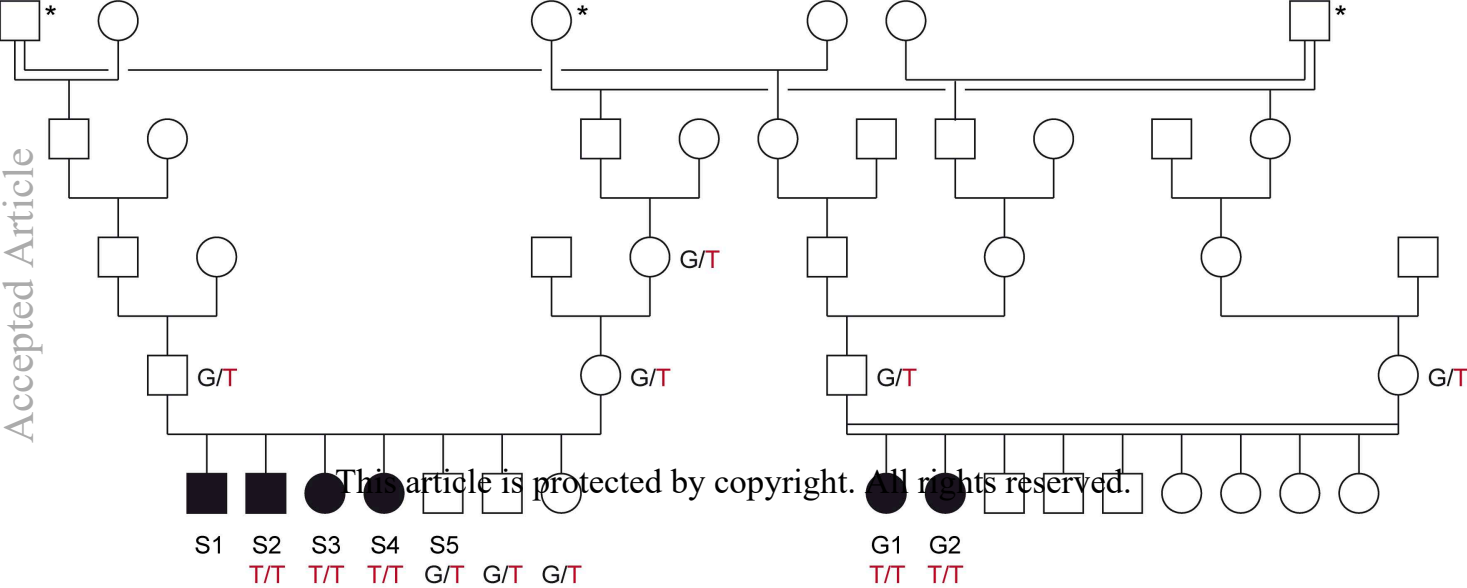




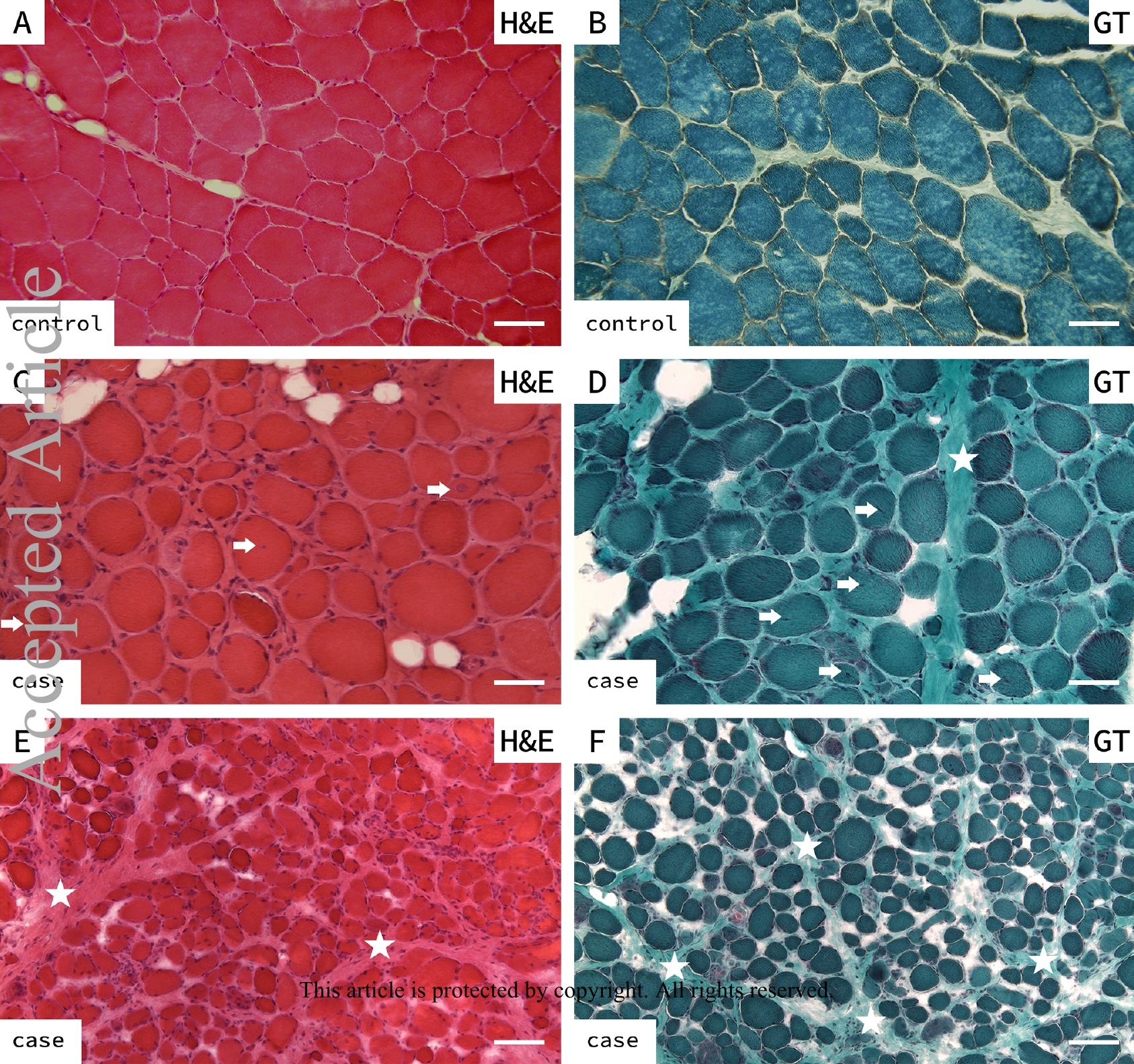




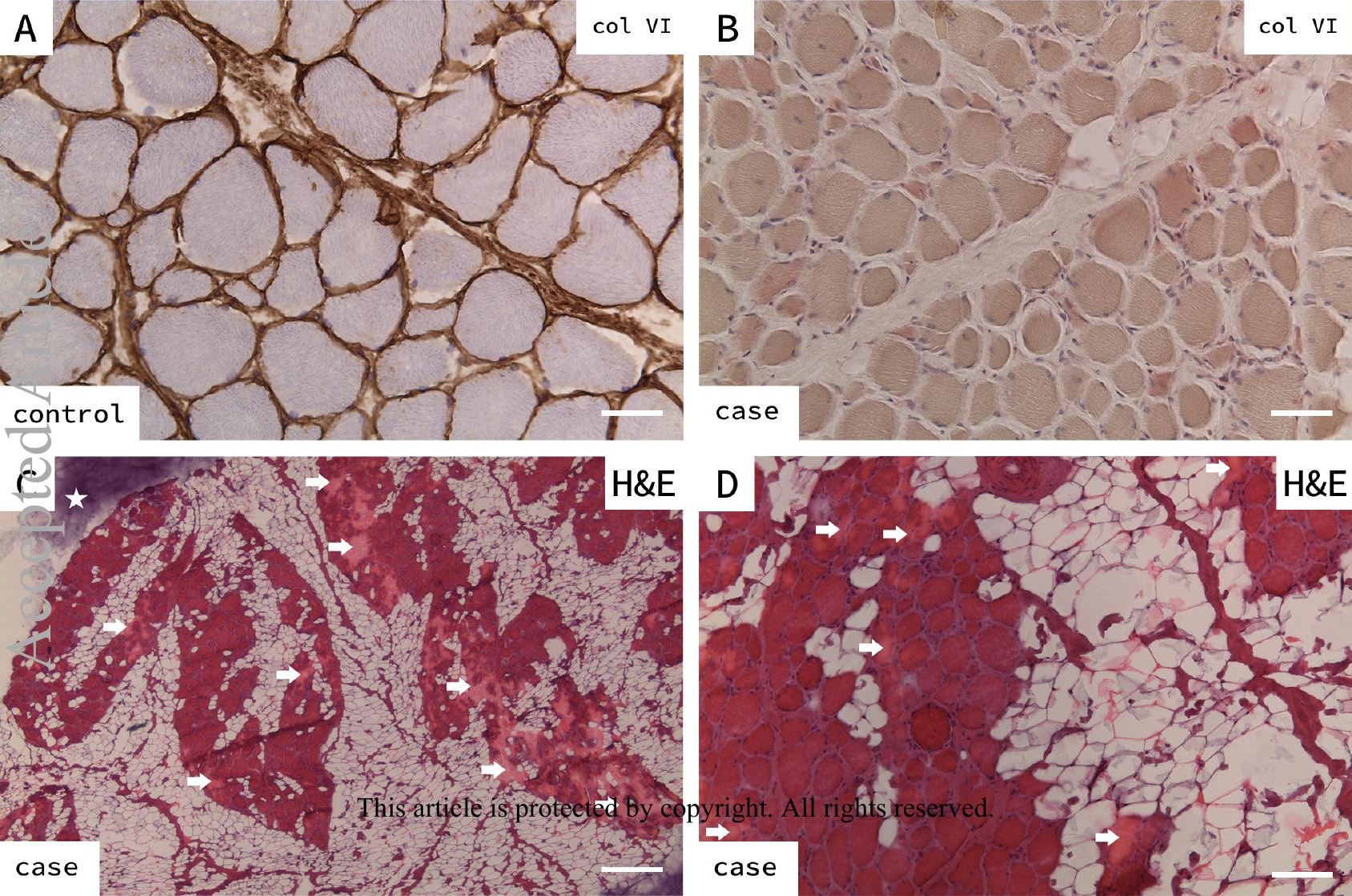


